\title{
Outcome of Hind Foot Arthrodesis by Expert Hind Foot Arthrodesis Nail
}

\author{
Debojyoti Mukharjee ${ }^{1}$, Parasambit Mukharjee ${ }^{2}$, Soham Mondal ${ }^{3}$ \\ ${ }^{1,2,3}$ Department of Orthopaedics, RG Kar Medical College, Kolkata, West Bengal, India.
}

\section{ABSTRACT}

\section{BACKGROUND}

Hind foot arthrodesis is the last resort for severe ankle pain and few hind foot pathologies like severe foot ankle deformity (varus or valgus), non-united distal tibia fracture, neuro-osteoarthropathy (Charcot's joint), osteoarthritis, post traumatic arthritis, rheumatoid arthritis with pseudoarthrosis and those with avascular necrosis of talus. This study was conducted to determine the outcome of hind foot arthrodesis by expert hind foot arthrodesis nail.

\section{METHODS}

30 study subjects who reported to our orthopaedic OPD, RG Kar Medical College, Kolkata with complaints of ankle pain during the study period were studied. Sample size estimation was done at conveniences. After obtaining informed consent from the study subjects, tibio-talo-calcaneal arthrodesis was performed. All patients were evaluated for pain scores using visual analog score (VAS) and American Orthopedic Foot Ankle Society Score (AOFAS) preoperatively and at $6^{\text {th }}, 8^{\text {th }}$ and $12^{\text {th }}$ month post operatively. All the data were entered and tabulated in Microsoft Excel 2016. The mean VAS and AOFAS scores were expressed as means.

\section{RESULTS}

Mean age of the participants was 55 years and males formed the majority (97.0\%). $16.7 \%$ had diabetes as a comorbidity. The duration of illness ranged from 5 months to 10 years. The mean VAS scores [pre-op, post-op $6^{\text {th }}, 8^{\text {th }}$ and $12^{\text {th }}$ month: $7,5,1$ and 0] showed steady decline with almost no pain from over 8 months. The AOFAS scores [pre-op, post-op $6^{\text {th }}, 8^{\text {th }}$ and $12^{\text {th }}$ month: $40,70,75$ and 80 ] showed improvement.

\section{CONCLUSION}

Overall, there were favourable outcomes in terms of reduction in pain and with improved functionality. Hence, hind foot arthrodesis by expert hind foot arthrodesis nail might be a good option in severe ankle pain patients.

\section{KEY WORDS}

Ankle Pain, Expert Hind Foot Arthrodesis, Tibiotalocalcaneal Arthrodesis, AOFAS Scores
Corresponding Author: Dr. Debojyoti Mukharjee, 2/A PC Sarkar Sarani, Kolkata-19, West Bengal, India, E-mail: debojyoti64@gmail.com

\section{DOI: $10.14260 /$ jemds/2020/855}

How to Cite This Article: Mukharjee D, Mukharjee $P$, Mondal S. Outcome of hind foot arthrodesis by expert hind foot arthrodesis nail. J Evolution Med Dent Sci 2020;9(52):3900-3903, DOI: $10.14260 /$ jemds/2020/855

Submission 17-12-2019,

Peer Review 27-10-2020,

Acceptance 03-11-2020,

Published 28-12-2020.

Copyright (C) 2020 Debojyoti Mukharjee et al. This is an open access article distributed under Creative Commons Attribution License [Attribution 4.0 International (CC BY 4.0)] 


\section{BACKGROUND}

Ankle joint provides plantar flexion and dorsiflexion whereas hind foot provides eversion and inversion. Fusion of ankle or hind foot may be required in arthritis or deformity, but pain management remains the primary goal, expert hind foot nail provides Tibio-Talo-Calcaneal (TTC nail) arthrodesis thus limiting ankle as well as hind foot movements.

\section{Objectives}

1. To assess the outcome of hind foot arthrodesis in patients with painful ankle.

2. To assess the outcome of ankle arthrodesis by arthrodesis nail.

3. To assess outcome of subtalar arthrodesis along with tibiotalar arthrodesis

\section{Ankle Biomechanics}

The ankle joint has the primary responsibility to manage the bodies weight with an against ground reaction force. Successful negotiation between these forces is critical for multiplanar motion and bipedal ambulation. Movements of talotibial joint is > supination $20>$ pronation 40 and of talocalcaneal joint is eversion and inversion.

\begin{tabular}{|c|c|c|c|c|}
\hline Axes & Description & $\begin{array}{c}\text { Angle with } \\
\text { Transverse } \\
\text { Plane }\end{array}$ & $\begin{array}{l}\text { Angle with } \\
\text { Sagittal } \\
\text { Plane }\end{array}$ & $\begin{array}{c}\text { Angle } \\
\text { with } \\
\text { Fronta } \\
\text { Plane }\end{array}$ \\
\hline tibiotalar joint & $\begin{array}{c}\text { lateral posterior and } \\
\text { planter to medial anterior } \\
\text { and dorsal along the line } \\
\text { of two malleoli }\end{array}$ & 8 degree & 82 degree & $\begin{array}{l}20-30 \\
\text { degree }\end{array}$ \\
\hline subtalar joint & $\begin{array}{c}\text { lateral posterior and } \\
\text { planter to medial anterior } \\
\text { and dorsal bisecting the } \\
\text { posterior facet of } \\
\text { calcaneum }\end{array}$ & 48 degree & 16 degree & 42 degre \\
\hline \multicolumn{5}{|c|}{ Table 1. Talotibial and Subtalar Movements } \\
\hline
\end{tabular}

\section{Position of Ankle Fixation}

- 1. Neutral flexion.

- 2.5-10 degree external rotation (comparable to opposite site).

- 5 degree valgus.

- Translation of talus posteriorly to align the posterior margin of tibia.

\section{Why This Position}

\begin{tabular}{|c|c|}
\hline Malposition & Effect \\
\hline $\begin{array}{l}\text { Excessive Internal } \\
\text { Rotation }\end{array}$ & $\begin{array}{c}\text { Increased stress on midfoot, knee, hip with overuse problem } \\
\text { of hip and knee }\end{array}$ \\
\hline $\begin{array}{l}\text { Excessive External } \\
\text { Rotation }\end{array}$ & $\begin{array}{c}\text { Foot rolls over medial side, hallux valgus, medial side knee } \\
\text { problem }\end{array}$ \\
\hline Planter flexed Fusion & Functional lengthening of limb, put stress on midfoot \\
\hline Dorsiflexed Fusion & $\begin{array}{c}\text { Concentrate ground impact on small area of heel which is } \\
\text { painful }\end{array}$ \\
\hline Varus Fixation & $\begin{array}{l}\text { Locks transverse tarsal articulation thus put stress on small } \\
\text { joints of midfoot especially the lateral side }\end{array}$ \\
\hline \multicolumn{2}{|r|}{ Table 2. Malposition and Its Effect } \\
\hline
\end{tabular}

Principles of Ankle Arthrodesis (Mannet al)

- Creation of broad flat cancellous surface that are placed into opposition to allow fusion.

- Arthrodesis should be stabilized with rigid fixation.

- Hind foot should be aligned with leg and forefoot should be aligned with hind foot to create plantigrade foot.

The hindfoot arthrodesis nail (TTC nail) is designed to fit anatomically in the calcaneus and distal tibial canal allowing anatomic fusion of the ankle. The nail provides secure fixation for ankle fusions with the use of a spiral blade for calcaneum ideal for patients with poor bone quality. With an arthrodesis nail-early mobilisation can be initiated after surgical procedure. Anaesthesia-spinal or general anaesthesia. And patient in prone position. Anterolateral approach for ankle joint i.e., incision is cantered at the ankle joint, parallel to the fourth metatarsal distally, and parallel to and between the tibia and fibula proximally. Dissection through the skin and subcutaneous tissues should proceed sharply with maintenance of full thickness skin flaps. Since the anterior compartment muscles arise from the anterior fibula, the incision is usually not extended more than seven centimetres above the ankle joint. Distally, the incision can extend as far as the talonavicular joint. Take care not to damage the superficial peroneal nerve which lies directly beneath the skin. This nerve invariably crosses the surgical incision proximal to the ankle joint. It should be identified, mobilized, and protected throughout the surgical procedure. The fascia over the anterior compartment of the distal tibia is incised sharply, beneath the superficial peroneal nerve. Distally, the extensor retinaculum is incised, and the anterior compartment tendons are all retracted medially. Proximally, the entire anterior compartment musculature, including the peroneus tertius, can then be mobilized and retracted medially. These muscles and tendons are usually easy to mobilize from the underlying anterior tibiofibular ligament, the periosteum of the distal tibia, and the joint capsule.

The fascia of the extensor digitorum brevis can be incised, with the muscle carefully dissected and retracted medially. This allows exposure of the talar neck for pin placement and distractor application. Proper location of the arthrotomy, preplanned to lie over the fracture, is critical to avoid unnecessary and damaging devascularization of fracture fragments. Proximally, the dissection is limited by the origin of the anterior compartment muscles from the fibula and from the interosseous membrane.

Application of a distractor intraoperatively greatly assists with articular visualization. Additionally, the distractor helps to align several of the major articular fragments. A $4 \mathrm{~mm}$ Schanz pin is placed transversely from lateral to medial at the talar neck through the surgical incision.

A second $4 \mathrm{~mm}$ Schanz pin is placed from lateral to medial at the tibia, proximal to the anticipated plate application. The pin placement in the talar neck, which is anterior to the axis of rotation of the talus, will produce ankle joint distraction and plantarflexion, maximizing articular visualization. The threaded rod of the small distractor is placed postero laterally to avoid interference with joint visualization. Followed by joint debridement and entry-guide wire inserted in the conjunction of two lines crossing medial to lateral malleolus and perpendicular to 2 nd toe on the sol further steps. 
Followed by reaming, measurements, nail insertion and compression of joint, calcaneal spiral blade insertion, Talus Lock and Proximal Lock.

\section{METHODS}

This is a longitudinal observational study conducted among thirty cases who underwent hind foot arthrodesis for ankle pain at RG Kar Medical College, Kolkata, during the study period from 2016 to 2019. The number of study subjects who presented to Orthopaedic OPD at R G Kar Medical College with history of ankle pain presented and consented to undergo hind foot arthrodesis during the study period were considered for the study. The subjects with severe foot ankle deformity (varus or valgus), non-united distal tibia fracture, neuro osteo arthropathy (Charcot's joint), osteoarthritis, post traumatic arthritis, rheumatoid arthritis with pseudoarthrosis and those with avascular necrosis of talus. Among 30 patients who presented with ankle pain, 18 patients were non united distal tibia fractures, 2 were neuro osteo arthropathy (charcots joint), 1 was osteoarthritis of ankle, 8 were having post traumatic arthritis and 1 was rheumatoid arthritis with pseudoarthrosis. After obtaining the informed consent from the study subjects, tibio talo calcaneal arthrodesis was performed. The study subjects among whom options other than joint fusion can give good results, like tendon transfer or balancing, osteotomies, mid-foot fusion etc, with presence of active infection were excluded from the study. All the patients were evaluated for pain scores using two scoring systems Visual Analogue Score (VAS) and American Orthopaedic Foot Ankle Society Score (AOFAS) preoperatively and post operatively at $6^{\text {th }}$ month, $8^{\text {th }}$ month and $12^{\text {th }}$ month. All the data was entered and tabulated in Microsoft Excel 2016. The continuous data like age, VAS and AOFAS scores were expressed in means and the discrete data like gender were expressed in proportions. The sample size estimation was also done at conveniences

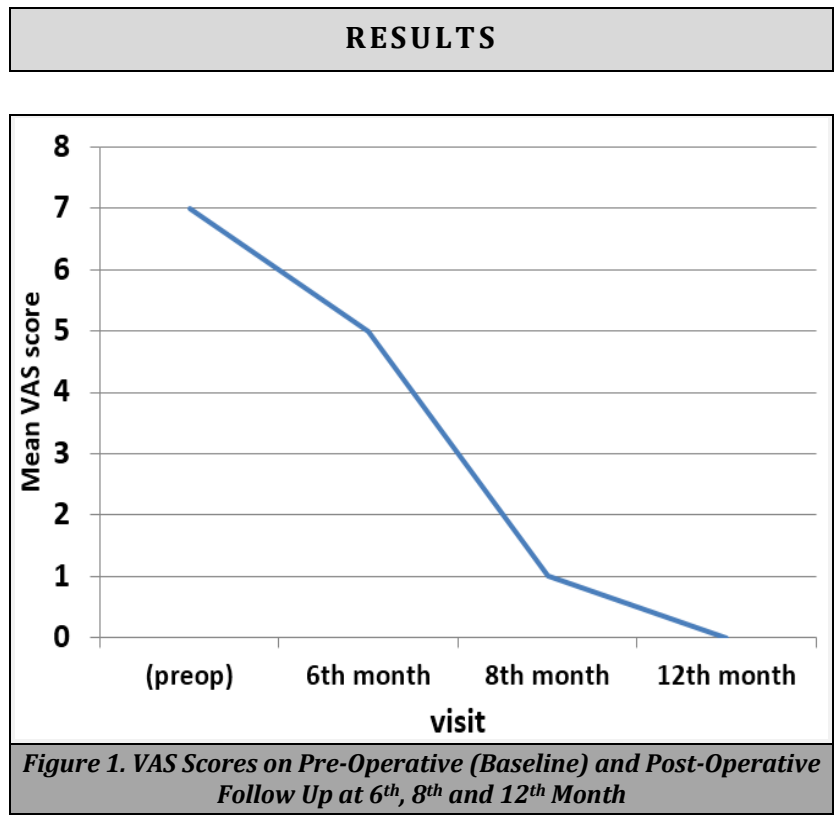

The mean age of the participants was $55 \pm 2.5$ years and it ranged from 48 to 65 years. Males were predominant (29 / 30, $97.0 \%$ ) and $16.7 \%$ had diabetes and the minimum duration of illness was 5 months and the maximum were 10 years. The mean VAS scores were $5 \pm 1.25,1 \pm 0.2$ and 0 during post op follow-up of $6^{\text {th }}, 8^{\text {th }}$ and $12^{\text {th }}$ month respectively and it showed steady decline with almost no pain from over 8 months. [Figure 1] AOFAS scores also showed improvement with mean pre-operative score being $40 \pm 15$ and $70 \pm 25,75 \pm 20$ and 80 \pm 35 during post-operative follow-up of $6^{\text {th }}, 8^{\text {th }}$ and $12^{\text {th }}$ month respectively. [Figure 2]

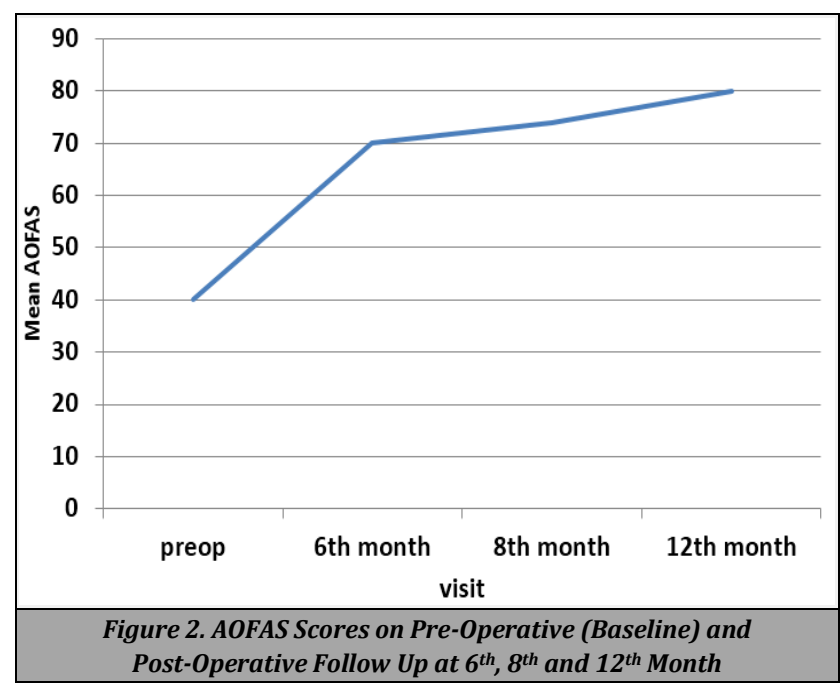

\section{DISCUSSION}

The present study reports a single-centre prospective series of tibio talar calcaneal arthrodesis using the Expert HAN implant. Our patients reported significant improvements in functional outcomes, and most were satisfied with the outcome of their surgery. The fusion rate was $100 \%$, and the overall rate of infection was with 1 case. It is evident that the patients in the present series were adequately treated with the TTCA using the HAN implant and overall achieved favourable outcomes.

Hind foot arthrodesis or tibio talar calcaneal arthrodesis remains the last resort for patients faced with intractable ankle and hindfoot pathologic entities. It is often the only salvage option before a below-the-knee amputation.1,2,3 Many studies have been reported on tibio talar calcaneal arthrodesis with promising results. ${ }^{4,5-10}$ However, a comparison between such studies is problematic owing to the heterogeneous patient cohorts. Nonetheless, the functional scores used in the present study, the SF-36 and AOFAS AHS, are widely used and allows for some degree of comparison. Our results are in tandem with the findings from other studies. ${ }^{4,11}$ A multicentre study of 38 patients from 7 participating centres across North America and Europe reported favourable functional improvements using the SF-36 and AOFAS Foot and Ankle Outcome scores in patients who underwent tibio talar calcaneal arthrodesis with the Expert HAN implant. ${ }^{3}$ Goebel et al $^{12}$ also reported significant improvements in the quality of life after tibio talar calcaneal arthrodesis, albeit using a straight nail construct. In the published data, although no study compared tibio talar calcaneal arthrodesis with straight 
nail versus curved nail designs, both designs appear to confer favourable functional outcomes.

The surgical goal of ankle arthrodesis is to obtain bony union between the tibia and talus with adequate alignment [slight valgus $\left(0^{\circ}-5^{\circ}\right)$ ], neutral dorsiflexion, and slight external rotation positions) in order to provide a pain-free plantigrade foot for weight bearing activities. There are many variations in operative technique including deferring approaches and differing fixation methods (internal or external fixation). Each technique has its advantage and disadvantages.

In our 30 cases 18 patients were non united distal tibia fractures, 2 were neuro osteo arthropathy (Charcot's joint), 1 was osteoarthritis of ankle, 8 were having post traumatic arthritis and 1 was rheumatoid arthritis with pseudoarthrosis. All patients went back to their employment soon after weight bearing is allowed and can perform their family duties. Among the 30 patients 15 were diabetic. In complications, soakage is the most common found in almost all cases needed re-dressing within $48 \mathrm{hrs}$. So forced limb elevation via BOHLAR-BRAUNE splint is done. Minor infection happened in 2 patients treated by oral antibiotics. Major infection occurred in one patient with uncontrolled diabetes and implant had to be removed after 1 yr. 2 months. All patients had their ankle fused on x ray.

\section{CONCLUSIONS}

Hind foot arthrodesis by expert hind foot arthrodesis nail provides good outcome and patient satisfaction. Ankle arthrodesis is an effective treatment option for end stage arthritis.

Data sharing statement provided by the authors is available with the full text of this article at jemds.com.

Financial or other competing interests: None.

Disclosure forms provided by the authors are available with the ful text of this article at jemds.com.

\section{REFERENCES}

[1] Papa JA, Myerson MS. Pantalar and tibiotalocalcaneal arthrodesis for post traumatic osteoarthrosis of the ankle and hindfoot. J Bone Joint Surg Am 1992;74(7):1042-9.

[2] Russotti GM, Johnson KA, Cass JR. Tibiotalocalcaneal arthrodesis for arthritis and deformity of the hind part of the foot. J Bone Joint Surg Am 1988;70(9):1304-7.

[3] Papa J, Myerson M, Girard P. Salvage, with arthrodesis, in intractable diabetic neuropathic arthropathy of the foot and ankle. J Bone Joint Surg Am 1993;75(7):1056-66.

[4] Hernández-Díaz C, Saavedra MÁ, Navarro-Zarza JE, et al. Clinical anatomy of the ankle and foot. Reumatol Clin 2013;8 Suppl 2:46-52.

[5] Rammelt S, Pyrc J, Agren PH, et al. Tibiotalocalcaneal fusion using the hindfoot arthrodesis nail: a multicenter study. Foot Ankle Int 2013;34(9):1245-55.

[6] Boer R, Mader K, Pennig D, et al. Tibiotalocalcaneal arthrodesis using a reamed retrograde locking nail. Clin Orthop Relat Res 2007;463:151-6.

[7] Haaker R, Kohja EY, Wojciechowski M, et al. Tibio-talocalcaneal arthrodesis by a retrograde intramedullary nail. Ortop Traumatol Rehabil 2010;12(3):245-9.

[8] Hammett R, Hepple S, Forster B, et al. Tibiotalocalcaneal (hindfoot) arthrodesis by retrograde intramedullary nailing using a curved locking nail: the results of 52 procedures. Foot Ankle Int 2005;26(10):810-5.

[9] Muckley T, Klos K, Drechsel T, et al. Short-term outcome of retrograde tibiotalocalcaneal arthrodesis with a curved intramedullary nail. Foot Ankle Int 2011;32(1):47-56.

[10] Grass R. Tibiotalocalcaneal arthrodesis using a distally introduced femur nail (DFN). Oper Orthop Traumatol 2005;17(4-5):426-41.

[11] Paola LD, Volpe A, Varotto D, et al. Use of a retrograde nail for ankle arthrodesis in Charcot neuroarthropathy: a limb salvage procedure. Foot Ankle Int 2007;28(9):967-70.

[12] Goebel M, Gerdesmeyer L, Muckley T, et al. Retrograde intramedullary nailing in tibiotalocalcaneal arthrodesis: a short-term, prospective study. J Foot Ankle Surg 2006;45(2):98-106. 